\title{
PRINCIPIO DE SUBSIDIARIEDAD Y MARGEN NACIONAL DE APRECIACIÓN. ARTICULACIÓN DEL SISTEMA INTERAMERICANO DE PROTECCIÓN DE DERECHOS HUMANOS CON LOS REGIMENES NACIONALES
}

\section{Alfonso Santiago}

Buenos Aires: Astrea, 2020, 264 páginas.

“-... Sólo puedes exigir a cada uno lo que cada uno puede hacer [...] La autoridad reposa, ante todo, sobre la razón. Si ordenas al pueblo que se arroje al mar, el pueblo hará la revolución. Yo tengo derecho a exigir obediencia porque mis órdenes son razonables".

Fragmento del diálogo entre el rey del asteroide 325 y el Principito.

De Saint-Exupéry (2019, p. 65).

De un tiempo a esta parte se han evidenciado nuevos desafíos en el Sistema Interamericano de Derechos Humanos (SIDH). Quizás, uno de los puntos más sensibles sea la coordinación de las relaciones de los Estados parte con los organismos internacionales creados en los acuerdos constitutivos de dicho Sistema. En este marco, Alfonso Santiago, en Principio de subsidiariedad y margen nacional de apreciación. Articulación del sistema interamericano de protección de derechos humanos con los regimenes nacionales, ofrece una respuesta "fuera del molde" a muchas de las preguntas que asedian a los operadores jurídicos frente al avance del Derecho Internacional de los Derechos Humanos (DIDDHH).

¿Cómo se armoniza el DIDDHH con los ordenamientos jurídicos nacionales? ¿Qué debe primar en caso de conflicto insalvable entre normas constitucionales y convencionales? ¿Quién tiene la última palabra en materia de derechos humanos? ¿Qué valor tienen las decisiones de la Corte Interamericana (Corte IDH)? ¿Puede subsistir la doctrina del control de convencionalidad? ¿Cuál es, en definitiva, el fundamento del "nuevo orden internacional"? ¿Cuáles son sus límites? Santiago afronta estos interrogantes a partir de un principio transversal 
a los sistemas de derechos humanos: el principio de subsidiariedad, y de lo que él describe como su "corolario": la doctrina del margen nacional de apreciación.

El trabajo condensa años de investigación: el autor fue uno de los primeros en explorar esta temática que hoy interpela a iusfilósofos, internacionalistas y constitucionalistas por igual ${ }^{1}$ y a la que aún rodea un halo de misterio en la región. Ya en 2013 Santiago ponía la lupa en la cuestión, en la comunicación que presentó ante el Instituto de Política Constitucional de la Academia Nacional de Ciencias Morales y Políticas, titulada "El principio de subsidiariedad en el Derecho Internacional de los Derechos Humanos". Sus credenciales en la materia se aprecian en la profundidad del estudio, en su actualización, en la original metodología con la que desarrolla los puntos cruciales y en el logrado complemento entre teoría jurídica y práctica jurisprudencial. La solidez del trabajo fue refrendada por pares en un formato de evaluación bajo el sistema "doble ciego", que no abunda en la publicación de libros y que le imprime a este un sello de calidad.

El desarrollo comienza con el surgimiento y la evolución del DIDDHH. El planteo es razonable: únicamente un repaso por la historia y por los sujetos involucrados desde el origen brindan el contexto adecuado para la justificación del principio de subsidiariedad como núcleo de los sistemas de protección de derechos humanos. Santiago va afinando el foco paulatinamente: del sistema universal (capítulo I) pasa al interamericano (capítulo II) para, finalmente, adentrarse en el derecho argentino, en su particular recepción constitucional del DIDDHH y en la relación de la Corte IDH con el máximo tribunal local (capítulo III).

La empresa se lleva adelante desde un enfoque primordialmente histórico, aspecto en el cual Santiago es una voz autorizada si se considera que ha encabezado un estudio colectivo con motivo de los cuarenta años de la Corte IDH, el cual no registra antecedentes en la región (Santiago y Bellocchio, 2018). Pero además este aporte se enriquece con una mirada iusfilosófica. El autor no evade las reflexiones acerca de la dignidad humana como fundamento del DIDD$\mathrm{HH}$ y del "carácter supremo" de ese principio, en la medida en que "apunta a tutelar lo que de universal y permanente se puede reconocer en la persona humana" (p. 11). A partir de esa premisa, se hace cargo de los debates que provocan tanto el proceso expansivo del DIDDHH como el papel de los órganos internacionales y el problema de la legitimidad democrática en la definición

1 En los últimos años, la doctrina argentina ha puesto la atención sobre el tema con notable énfasis. Entre otras, merece destacarse la obra conjunta El margen nacional de apreciación: Aportes a la soberanía jurídica de los Estados, que fue prologada por el propio Santiago (Díaz Solimine y Díaz Solimine, 2020). 
de los contenidos fundamentales de esos derechos. Sobre esto, explica cómo la jurisprudencia de los tribunales internacionales (y también locales) ha procurado ampliar los contenidos obligatorios e indisponibles, más allá de los textos de los tratados y las inevitables controversias que estas posturas aparejan. Aquí cobran especial relevancia las advertencias que el autor formula, en línea con Benedicto XVI, sobre el riesgo que entraña la desnaturalización de los derechos humanos, siempre que se funden en una moral relativista, así como la amenaza que supone una excesiva "inflación" cuantitativa de "pseudo-derechos" que conlleve su desvalorización (p. 21).

Más adelante, vuelve sobre el fenómeno de la expansividad del DIDDHH, al considerar el establecimiento del tribunal regional como uno de los hitos del SIDH. A pesar del balance positivo al que arriba sobre su desempeño, indica con agudeza que para alcanzar una "plena madurez institucional”, el tribunal debe aceptar la necesidad de "consensuar [...] con otros actores, entre ellos, los Estados parte que le dieron vida” (pp. 52-53). La aplicación de estas ideas al escenario jurídico argentino lo lleva, por ejemplo, a reconocer que existe un proceso dialógico activo en dirección "descendente", que no tiene correlato en sentido "ascendente".

El capítulo IV reúne el corazón de la investigación. Santiago argumenta a favor de la vigencia del principio de subsidiariedad en el derecho internacional como un criterio "iluminador" para "articular, coordinar y armonizar las normativas y jurisdicciones nacionales con las internacionales en materia de protección de los derechos humanos" (p. 89). Se adentra en las raíces de aquel principio y, con acierto, las remonta a la antigüedad grecorromana y al pensamiento de Santo Tomás, para luego mostrar su desarrollo indiscutible en el más reciente Magisterio Social de la Iglesia. Destaca también el fundamento del principio de subsidiariedad: la protección de la persona humana, de los "grupos intermedios" y, desde la perspectiva internacional, de los "Estados nacionales" (p. 91). Se refiere, finalmente, a las manifestaciones que la subsidiariedad posee en el derecho internacional positivo, tanto en el sistema universal como en el interamericano y el europeo. Incluso, en este último caso, el autor anticipa una inminente reforma a la Convención Europea de Derechos Humanos (p. 141) (la adopción del Protocolo No 15, que efectivamente entraría en vigor el 1 de agosto de 2021, con posterioridad a la publicación del libro). ${ }^{2}$ Esa reforma adicionó una referencia explícita al principio de subsidiariedad y al margen de apreciación en el Preámbulo

2 Cfr. artículo $1^{\circ}$ del Protocol No. 15 amending the Convention for the Protection of Human Rights and Fundamental Freedoms, Strasbourg, 24/06/2013. Le agradecemos este dato al profesor Alfredo M. Vítolo. 
de aquella Convención, lo que evidencia que el tópico desarrollado en la obra también tiene absoluta relevancia del otro lado del Océano.

Santiago se detiene en el principio de subsidiariedad en su doble dimensión. Por un lado, presenta una dimensión sustantiva, que determina que el DIDDHH no sustituye el derecho local, sino que lo completa y refuerza, con respeto por la diversidad y el contexto concreto de cada comunidad. Por otro lado, encara la dimensión procesal del principio de subsidiariedad, criterio organizador por el que se reconoce prioridad a las autoridades domésticas para garantizar la vigencia de los derechos humanos y solo ulteriormente se admite la supervisión de los tribunales internacionales. El capítulo culmina con un recorrido de las decisiones de la Corte IDH, más cercanas en el tiempo, en las que se ha recogido el principio de subsidiariedad. Tal comprensión le permite caracterizar la novedosa (y compleja) relación entre el SIDH y los Estados parte. Fijada la semblanza de ese vínculo, se anima a esbozar pautas de interconexión normativas, procesales, axiológicas e institucionales que podrían afianzar el nexo entre el sistema regional y los domésticos (capítulo V).

La obra de Santiago no representa una cerrazón hacia el DIDDHH. Por el contrario, él se esfuerza en señalar que la indiferencia de los tribunales internacionales respecto a principios basales, como el de subsidiariedad, y la utilización estratégica del sistema regional para zanjar debates aún abiertos en el ordenamiento interno minan el prestigio del tribunal y menoscaban la autoridad jurídica de sus decisiones. De este modo, su propuesta constituye un llamado de atención sobre la extensión de las obligaciones asumidas por los Estados -tanto a nivel internacional como nacional-, con el fin de garantizar la efectividad del sistema, el cumplimiento de las decisiones de sus órganos y la permanencia de los Estados que lo conforman. Precisamente, Santiago se empeña en "tender puentes" y no en construir murallas: su posición es indudablemente dialógica.

Uno de aquellos puentes que él encuentra para facilitar la interconexión del sistema nacional con el internacional es el margen nacional de apreciación, a cuya exploración dedica buena parte del libro. El capítulo VI proporciona un análisis teórico de esta doctrina jurídica, criterio jurisprudencial y técnica hermenéutica, en el que se exploran sus fundamentos y se sustenta rigurosamente su compatibilidad con el respeto al contenido esencial de los derechos humanos. $^{3}$

Santiago ve en el margen nacional de apreciación un mecanismo no traumá-

3 La pacífica y necesaria concatenación entre el principio de subsidiariedad y el margen nacional de apreciación, trazada con solvencia por Santiago, permite ahuyentar las preocupaciones de quienes 
tico para solucionar el binomio universalismo-particularismo. Justamente, su aplicación exige el respeto de un espacio de maniobra -"un cierto grado de libertad" (p. 137) - a los Estados parte y, en paralelo, la "modestia" de los órganos de tratados (p. 151). En este sentido, se destaca la mirada realista del derecho, en tanto -sin desconocer aquello que es necesario- el académico asume las contingencias y diferencias propias del obrar humano y de su cultura. Una vez más, en este capítulo, la teoría se potencia con un formidable análisis jurisprudencial y comparativo, que contrasta las decisiones de la Corte Europea de los Derechos Humanos con las provenientes de la Comisión Interamericana y de la Corte IDH en cuestiones análogas.

La investigación se completa con un "Apéndice documental", que añade datos estadísticos y gráficos ilustrativos del funcionamiento de la Corte IDH (Anexo I) y una reproducción de la Declaración sobre el Sistema Interamericano de Derechos Humanos de 2019, firmada por Argentina, Brasil, Chile, Colombia y Paraguay (Anexo II). Dicha declaración constituye un verdadero llamado de atención de esos países en orden al reconocimiento de un margen nacional de apreciación, por ende, es prueba irrefutable de la relevancia jurídica y política de la temática en la región. Como se ha apuntado, hay allí una demostración del interés de los Estados parte en la subsistencia del SIDH, pues los suscriptores han manifestado inquietudes legítimas que traslucen la voluntad de mejorar su funcionamiento (Paúl, 2020, pp. 70-71, 80).

Asimismo, la obra reseñada presenta una construcción sólida del DIDDHH sobre los cimientos del principio de subsidiariedad. Se trata de un libro de consulta obligada para especialistas avezados, pero también de interés para la enseñanza universitaria de la materia. Cabe añadir que el patrimonio jurisprudencial que recoge Santiago resulta sin duda valioso para el profesional que, con frecuencia, ve inundada su cotidianidad con pretensiones formuladas en clave de derechos humanos.

Principio de subsidiariedad y margen nacional de apreciación... es un novedoso abordaje del SIDH, aunque sus conclusiones pueden extenderse a cualquier sistema de protección de los derechos humanos. El autor proporciona herramientas no solo para comprender el solapamiento de órdenes jurídicos, sino también para desarticular obstáculos procedimentales, competenciales y hermenéuticos que se interponen en la protección de los derechos humanos. Allí abrevarán quienes, preocupados como el autor por el desenlace de las tenden- 
cias internacionalistas, transhumanistas y gnosticistas, pretendan alzar su voz para que el sistema conserve su esencia.

Por lo demás, sus postulados acerca del funcionamiento institucional del SIDH y del resguardo de la autonomía de los Estados renuevan los incansables debates que suscita el DIDDHH. Las reflexiones a las que arriba al respecto se alinean -y deben complementarse- con una verdad subyacente, a la que Santiago alude en diversas oportunidades: la del fundamento de los derechos humanos (Glendon, 1999) y sus correlativos deberes, a menudo olvidados (Quintana, 2017).

Con espíritu conciliador, Alfonso Santiago llama a la prudencia de los organismos locales e internacionales y ofrece un camino a transitar para evitar que el sistema pierda el rumbo. Después de todo, no debe pedírsele al DIDDHH más de lo que puede ofrecer.

Florencia Ratti

Pontificia Universidad Católica Argentina

florenciaratti@uca.edu.ar

Sofía Calderone

Pontificia Universidad Católica Argentina

sofiacalderone@uca.edu.ar

\section{Bibliografía}

De Saint-Exupéry, A. (2019). El Principito (Trad. P. Gómez Carrizo). Biblok.

Díaz Solimine, O. L. (Dir.) y Díaz Solimine, I. L. (Coord.). (2020). El margen nacional de apreciación: Aportes a la soberanía jurídica de los Estados. Astrea.

Glendon, M. A. (1999). Foundations of Human Rights: The Unfinished Business. American Journal of Jurisprudence, 44(1). https://scholarship.law.nd.edu/ajj/vol44/iss1/1.

Nash Rojas, C. (2018). La doctrina del margen de apreciación y su nula recepción en la jurisprudencia de la Corte Interamericana de Derechos Humanos. CDI-Anuario Colombiano de Derecho Internacional, (11), 71-100. https://doi.org/10.12804/revistas.urosario.edu.co/ acdi/a.6539. 
Paúl, A. (2020). ¿Una paradoja interamericana? Chile, un Estado que cumple las sentencias del Sistema Interamericano de Derechos Humanos, pero que impulsa su reforma. Revista de Investigações Constitucionais, 7(1), 59-85. https://doi.org/10.5380/rinc.v7i1.70231.

Quintana, E. M. (2017). Dignidad y deberes humanos. Prudentia Iuris, (83), 73-94.

Santiago, A. (2013). El principio de subsidiariedad en el Derecho Internacional de los Derechos Humanos (comunicación presentada en la sesión privada del Instituto de Política Constitucional). Academia Nacional de Ciencias Morales y Políticas. https://www.ancmyp.org.ar/user/files/02-Santiago13.pdf.

Santiago, A. y Bellocchio, L. (Dirs.). (2018). Historia de la Corte Interamericana de Derechos Humanos. La Ley. 
